\title{
Case study of Sex-avoidance and Anxiety Disorder
}

\author{
Muhammad Zafar Iqbal* \\ Department of Hypnotherapist and Psychotherapist, Islamabad, Pakistan
}

*Corresponding author: Muhammad Zafar Iqbal, Department of Hypnotherapist and Psychotherapist, Islamabad, Pakistan.

Received Date: July 08, 2019

Published Date: July 12, 2019

\begin{abstract}
Background: This document pertains to the case study of Sex Avoidance and Anxiety Disorder.

Case presentation: The subject of the disorder was Mrs. Z.R. (Initials instead of real name), age 28 years being a Housewife. The client was referred to my clinic by an old client. She had been under treatment by different clinical psychologists, most of them used CBT but nothing good came out of the treatment. She visited my clinic along with her husband. Client told me that all day she has this feeling of apprehensiveness all over her. She avoided facing her husband when he returns home after the duty. In the night whenever her husband tries to come near her and tries to hold her in his arms, her heart starts palpitating and she bear feelings of fearfulness resulting in her whole body being shivering and sweating out. She usually sleeps alone and not with her husband and if by chance it happens so, she fails to sleep all the night. Another specific symptom about which the client informed therapist was that she felt fear and restlessness especially when her husband tries to grip her at under-neck as some husbands do while making love to their wives at the time of sexual intercourse. Client's husband informed the therapist that at times she becomes aggressive without any apparent reason.
\end{abstract}

Management \& Results: The assessment was made after taking semi-structured interviews to Mrs. Z.R. and her husband. In the light of assessment and as per [1] Mrs. Z.R was diagnosed for 'Sex Avoidance and Anxiety disorder'. After diagnosis, treatment was started in the light of FSIT method. Five sessions per week and a total of 55 sessions were conducted. It was observed that there were pre and post- assessment differences in personality and behavior of Mrs. Z.R. that insures the efficacy of FSIT.

Conclusion: In the course of treatment, the client and her husband reported about the positive behavioral change in the client's life. Clinical observations during treatment also indicated a gradual positive change in patient's personality. The difference between pre-assessment and postassessment confirmed precision of hypotheses and efficacy of FSIT.

Keywords: Sex Avoidance and Anxiety Disorder, Fear-Stimuli Identification Therapy (FSIT), Behavioral Change

\section{Introduction}

The major purpose of this particular case study was to reaffirm and prove the efficacy of Fear-Stimuli Identification Therapy (FSIT) on empirical grounds. It was also intended to use FSIT in order to eliminate the symptoms of Sex avoidance and Anxiety Disorder Mrs. Z.R. was suffering from. This particular therapeutic method was already used successfully to remove the symptoms of various disorders in different cases [2-11].

\section{Symptoms}

- $\quad$ Aggressive behavior

- $\quad$ Sleeplessness

- Headache in Occipital region

- $\quad$ Sweating

Fear Stimuli Identification Therapy (FSIT): Fear-Stimuli Identification Therapy (FSIT) is based upon the perception that some of the incidents (mostly the sudden incidents) in the early age of a child become stimuli for fear instinct which cast negative effects over the personality of a child and becomes reason for one or the other type of disorder. FSIT investigates and digs out such events from a person's unconscious, which play as stimuli for fear instinct. In a later stage of life, if a person happens to face a situation or pass through an event having resemblance to that which he/ she had already faced in her/his childhood or early age of life, the present event becomes a strong stimulant for fear instinct as the previous incident is recalled.

\section{Case Presentation}

Prior to treatment/intervention, a brief description of a patient's social and family environment was obtained in order to comprehend the main causes of Mrs. Z.R.'s disorder.

Personal history: Mrs. Z.R. was 28 years old housewife. However, on account of her feelings of apprehensiveness and 
unpleasant relations with her husband made her life miserable. Heart palpitation, shivering and extra-ordinary sweating indicated her as a patient of anxiety. She feared for break-up of conjugal relations.

Social history: Mrs. Z.R. was a graduate and owner of sociable manners and had an impressive inclination to remain among her female friends (not males) and social gatherings. However, she isolated herself from society and friends after marriage and preferred to remain in isolation for most part of time. This attitude added to her depression in her marital life.

Family history: No family history of Sex Avoidance or Anxiety Disorder or any other psychological/psychiatric disorder was found.

Medical / Past psychiatric history: Mrs. Z.R. had no special medical/psychiatric problems in her childhood or pre-marital life.

\section{Management \& Results}

\section{Participants: Mrs. Z.R. (client)}

Materials: No specific material used in this case study.

Procedure: In the first session, semi-structured interview was conducted with Mrs. Z.R. and her husband. An assessment was made in the light of these interviews as the reasons/causes of the disorder were dug out. Diagnostic and Statistical Manual for Mental Disorders was consulted in order to identify the type of disorder. In 54 subsequent sessions, Mrs. Z.R. was asked to write down on specific topics designed by therapist. Cross-questioning was carried out over the ideas mentioned in the writings. After diagnosis of disorder, treatment was started in the light of FSIT method. Five sessions per week and total of fifty-five sessions were conducted.

Assessment: Following facts were explored on conducting the semi-structured interview

At the age of four or five years, during child play her eldest cousin grabbed her throat jokingly to make her silent, restraining her from making unnecessary noises during the play. At the age of seven years, one day her mother sent her to street grocery to bring utilities for home. There, at the shop, the shopkeeper, on finding a chance made her sit in his lap and started kissing her all over her body. He also tangled her legs with his own legs to make wide body contact. After few months her neighbor hugged her tightly. All these three incidents became stimulus lead to the fear-instinct which arouses whenever someone i.e. her husband try to grab her through arms. The act of love made her recall the abuse she had faced in her childhood.

Treatment: After taking history, it was diagnosed that client was suffering from Sex Avoidance and Anxiety Disorder and the treatment was carried out accordingly

- $\quad$ As per procedure of SFW (Specific Free Writing; one of FSIT procedures), client was asked to pen down her ideas on the topic "Grip". Client was asked to write down her ideas freely and wherever she feels stuck or blank-minded, she would put a 'cross mark' on paper on that specific point. As per her ideas and writing, it was found that there are a fewer crosses on the paper, but the ideas mentioned were absurd and abrupt. She told that during the process of writing she felt burden at the occiput along with pain and burden on her shoulders. Client was cross-questioned regarding her writing. After 30 minutes while the cross-questioning process was in progress, she went into a lighter spell of drowsiness. The symptoms of burden over the shoulders, heaviness in the occiput region and drowsiness were the signs of resistance by the unconscious mind. The resistance proved that negative association for grip is present in client's unconscious level mind. In the same pattern she was asked to write down her ideas on the topics of 'male', 'sex' and 'sexabuse' in the subsequent sessions. Relatively excessive signs of crosses found in the writing on the topic of sex-abuse. State of drowsiness, burden on shoulders and in occiput region was also excessive during the process of writing on this particular topic as compare to other topics. Negative association for sex and male as discovered in the client's unconscious level of mind, though not so severe in intensity, was due the experience of sex abuse, the client suffered through in her childhood.

- In the last sessions of treatment, the negative association of unconscious mind with the act of gripping was eliminated. Negative association with male and sex was also neutralized. In this way the causes for Sex Avoidance and Anxiety Disorder were removed and client recovered from disorder completely.

\section{Results}

In the course of treatment, the client and her husband as well reported about the Positive change in client's behavior and conduct. The sexual relations of couple restored to normality. The therapist was also informed that client no more behaves aggressively. Sleeping problem of the client was also rectified. Clinical observations during treatment also indicated a gradual positive change in her personality. The difference between pre-assessment and postassessment confirmed precision of hypotheses and efficacy of FSIT. Feedback was obtained on weekly basis for a period of three months from Mrs. Z.R. and her husband about any possible reappearance of symptoms of the disorder and this was confirmed that there was no reoccurrence of the disorder's symptoms anymore.

\section{Complicating factors}

- $\quad$ The causes of Sex Avoidance and Anxiety Disorder were determined as the act of sex abuse incidents in childhood of client.

- The act of gripping by the husband which created a sense of fear in client was a result of experience of her childhood when her eldest cousin gripped her over the under-neck.

- $\quad$ Five sessions per week for treatment were necessary for recovery.

\section{Discussion}

Before visiting the therapist clinic, Mrs. Z.R. had have already consulted different clinical psychologists. CBT was adopted to 
cure the disorder by previously conducted clinical psychologists, which did not bring about any positive results. The resistance of unconscious level of mind was a barrier, and when it was identified by the way of free writing on specific topics and cross questioning this very barrier was also removed.

\section{Recommendations}

- It is recommended that a study should be carried out focusing upon Fear instinct.

- FSIT should be used for the treatment whenever symptoms of any disorder are conditional to fear instinct.

- The Therapist should focus upon the causes of the problem for the treatment.

\section{Acknowledgement}

None.

\section{Conflicts of Interest}

No conflict of interest.

\section{References}

1. American Psychiatric Association (2000) Diagnostic and statistical manual of mental disorders (DSM-IV-TR). DC: American Psychiatric Association, Washington, USA.
2. Ejaz M, Iqbal MZ (2016) Case Study of Major Depressive Disorder. J Clin Case Rep 6: 698.

3. Iqbal MZ, Awan SN (2016) Case Study of Genophobia and Anxiety. J Depress Anxiety S2: 013.

4. Iqbal MZ, Bibi S (2017) Case Study of Panic Attacks. J Psychol Psychother 7: 306 .

5. Iqbal MZ, Bibi S (2016) Treatment of Psychosis through Fear-Stimuli Identification Therapy (FSIT): A Case Report. Brain Disord Ther 5: 221.

6. Iqbal MZ, Ejaz M (2016) Case Study of Schizophrenia (Paranoid). J Clin Case Rep 6: 779.

7. Iqbal MZ, Ejaz M (2016) Case Study of Functional Neurological Disorder (Aphonic). J Psychol Psychother 6: 243.

8. Iqbal MZ, Un Awan SN (2016) Case Study of Major Depression. J Med Diagn Meth 5: 214.

9. Iqbal Z (2015) Case of Anxiety. J Psychol Clin Psychiatry 2(4): 00079.

10. Muhammad Zafar Iqbal (2017) Case study of Obsessive-Compulsive Disorder (OCD). Journal of Behavioral Health 6(2): 99-02.

11. Muhammad Zafar Iqbal (2019) Case Study of Obsessive-Compulsive Disorder (OCD). On J Complement \& Alt Med. 1(2). 